\title{
Everolimus improved renal function without reducing the size of a kidney angiomyolipoma in a patient with tuberous sclerosis complex: a case report
}

\author{
Akira Ashida ${ }^{1 *}$ (D) Hideki Matsumura ${ }^{1}$, Yuko Fujii ${ }^{1}$, Hyogo Nakakura² ${ }^{2}$ Akihiko Shirasu ${ }^{3}$ and Hiroshi Tamai ${ }^{1}$
}

\begin{abstract}
Background: Tuberous sclerosis complex is an autosomal dominant genetic disorder that affects multiple organ systems and can result in tumors in the brain, skin, heart, and kidneys; it may also cause neurological symptoms. About 1 to $7 \%$ of patients develop end-stage renal disease due to bilateral renal angiomyolipoma. We herein describe a patient with a bilateral large kidney angiomyolipoma whose residual renal function was temporarily improved with everolimus treatment.

Case presentation: A 39-year-old man was diagnosed with tuberous sclerosis complex associated with an angiomyolipoma that was first detected at 12 years of age and had enlarged to a size that completely filled the bilateral kidneys. Although his kidney function was poor at the start of everolimus treatment as indicated by a creatinine-based estimated glomerular filtration rate of $13.7 \mathrm{~mL} / \mathrm{min} / 1.73 \mathrm{~m}^{2}$, his kidney function recovered with an annual increase in the glomerular filtration rate of $4.57 \mathrm{~mL} / \mathrm{min} / 1.73 \mathrm{~m}^{2}$ without morphological changes or a reduction in the size of the angiomyolipoma after everolimus treatment. As a result, we were able to delay the initiation of renal replacement therapy for more than 1 year.

Conclusions: Even in patients with tuberous sclerosis complex who exhibit decreased renal function, everolimus treatment can retain the renal function and delay introduction of dialysis without a reduction in the size of the renal angiomyolipoma. The pathophysiological mechanisms for the deterioration of renal function in patients with tuberous sclerosis complex may not involve renal parenchymal loss secondary to angiomyolipoma growth only but may also involve other mechanisms including glomerular hypertrophy and hyperfiltration associated with mTOR complex 1 overactivity.
\end{abstract}

Keywords: Everolimus, Tuberous sclerosis complex, Angiomyolipoma, mTOR inhibitor, Glomerular hyperfiltration

\section{Background}

Tuberous sclerosis complex (TSC) is an autosomal dominant genetic disorder that affects multiple organ systems and can result in tumors in the brain, skin, heart, and kidneys; it may also cause neurological symptoms. Symptoms vary among the multiple organ systems affected by TSC depending on patient age. Up to $80 \%$ of adult patients with TSC develop angiomyolipoma, which is typically bilateral and

\footnotetext{
* Correspondence: ped006@osaka-med.ac.jp

'Department of Pediatrics, Osaka Medical College, 2-7 Daigaku-machi,

Takatsuki City, Osaka 569-8686, Japan

Full list of author information is available at the end of the article
}

multiple. An estimated 40\% of patients with TSC develop reduced kidney function, and the overall risk for end-stage renal disease (ESRD) ranges from 1 to $7 \%$ [1-4].

Discovery of the mTOR pathway as the pathophysiological cause of TSC led to a new therapeutic approach involving administration of an mTOR inhibitor to combat the disease. The therapeutic effects, especially the antiproliferative effects, of mTOR inhibitors have been investigated in numerous clinical studies.

We herein describe a patient with a bilateral large TSC-associated angiomyolipoma whose residual renal

(c) The Author(s). 2018 Open Access This article is distributed under the terms of the Creative Commons Attribution 4.0 International License (http://creativecommons.org/licenses/by/4.0/), which permits unrestricted use, distribution, and 
function improved and for whom the initiation of renal replacement therapy was delayed.

\section{Case presentation}

A 39-year-old man was diagnosed with TSC associated with facial angiofibromas, fibrous cephalic plaques, shagreen patches, brain subependymal nodules, and angiomyolipoma in the kidneys and liver. His height was $177 \mathrm{~cm}$, and he weighed $119.0 \mathrm{~kg}$ (body mass index $38.0 \mathrm{~kg} / \mathrm{m}^{2}$ ). He had developed an infantile spasm at 5 months after birth, and his seizures showed refractory epilepsy associated with delays in psychomotor development. He had a severe intellectual disability and cognitive impairment with autism spectrum disorder, so-called TSC-associated neuropsychiatric disorders (TANDs). Abdominal ultrasonography detected multiple small masses in the bilateral kidneys and fatty liver at 12 years of age. At 28 years of age, an abdominal computed tomography (CT) scan showed a large simple cyst in the right kidney and multiple angiomyolipoma completely filling the bilateral kidneys. His kidney function had gradually decreased to a creatinine-based estimated glomerular filtration rate (Cr-eGFR) of $13.7 \mathrm{~mL} /$ $\min / 1.73 \mathrm{~m}^{2}$ (Fig. 1). At that time, laboratory tests revealed a white blood cell count of $8320 / \mu \mathrm{L}$, hemoglobin level of $9.1 \mathrm{~g} / \mathrm{dL}$, platelet count of $39.1 \times 10^{4} / \mu \mathrm{L}$, blood urea nitrogen level of $57 \mathrm{mg} / \mathrm{dL}$, uric acid level of $8.8 \mathrm{mg} / \mathrm{dL}$, cystatin C level of $3.4 \mathrm{mg} / \mathrm{dL}$, cystatin C-based estimated glomerular filtration rate (cys-eGFR) of $17.9 \mathrm{~mL} / \mathrm{min} /$ $1.73 \mathrm{~m}^{2}$, sodium level of $132 \mathrm{mEq} / \mathrm{L}$, potassium level of $4.5 \mathrm{mEq} / \mathrm{L}$, chloride level of $103 \mathrm{mEq} / \mathrm{L}$, calcium level of $9.0 \mathrm{mg} / \mathrm{dL}$, inorganic phosphorus level of $3.2 \mathrm{mg} / \mathrm{dL}$, and iron level of $71 \mathrm{mg} / \mathrm{dL}$. Because of his TANDs, we considered that initiation of dialysis would present many difficulties for him and his family. Therefore, he was administered everolimus to preserve his kidney function and delay the initiation of renal replacement therapy. Additionally, he began strict weight loss therapy with a nutritional support service. Although the rate of Cr-eGFR decline had been $5.6 \mathrm{~mL} / \mathrm{min} / 1.73 \mathrm{~m}^{2}$ per year before everolimus treatment, his Cr-eGFR recovered at an increased rate of $4.57 \mathrm{~mL} /$ $\min / 1.73 \mathrm{~m}^{2}$ per year and reached $20.1 \mathrm{~mL} / \mathrm{min} / 1.73 \mathrm{~m}^{2}$ after 4 months of everolimus treatment (Fig. 1). At that time, the cystatin $\mathrm{C}$ level was $2.6 \mathrm{mg} / \mathrm{dL}$ (cys-eGFR, $25.0 \mathrm{~mL} / \mathrm{min} / 1.73 \mathrm{~m}^{2}$ ). We expected that with everolimus treatment, his residual renal function would be preserved as the angiomyolipoma mass decreased to a size comparable with that of the residual normal renal tissue. However, there was no morphological change in his bilateral kidney angiomyolipoma on CT findings before and after everolimus treatment, and his bilateral kidney size, measured as

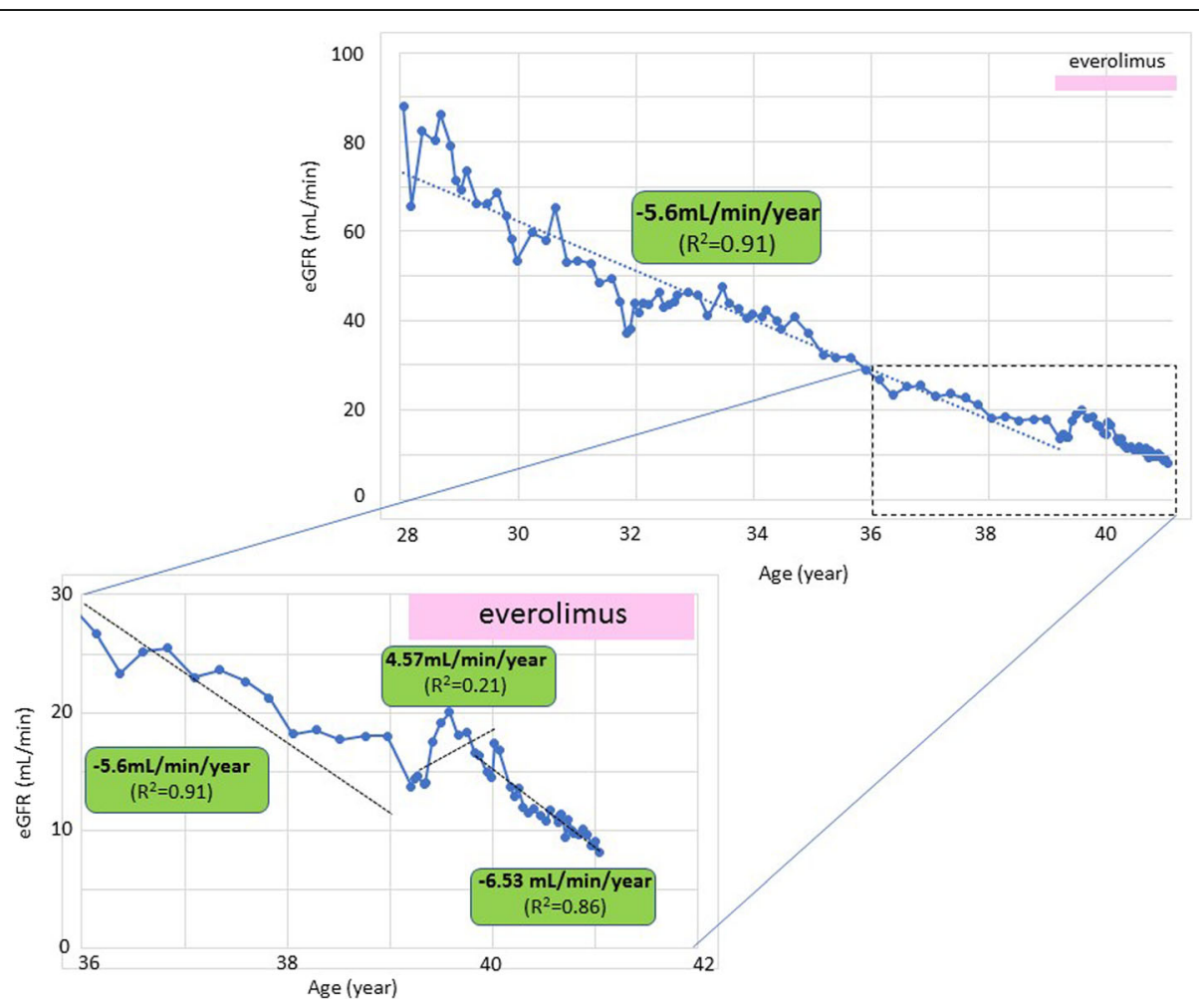

Fig. 1 Changes in eGFR with everolimus treatment. The rate of Cr-eGFR decline was $-5.6 \mathrm{~mL} / \mathrm{min} / 1.73 \mathrm{~m}^{2}$ per year before initiation of everolimus treatment. After the initiation of everolimus treatment, the Cr-eGFR recovered to $20.1 \mathrm{~mL} / \mathrm{min} / 1.73 \mathrm{~m}^{2}$ after increasing by $4.57 \mathrm{~mL} /$ $\mathrm{min} / 1.73 \mathrm{~m}^{2}$ per year. Cr-eGFR, creatinine-based estimated glomerular filtration rate 
the longitudinal length of each kidney and calculated from slice counts of horizontal CT images, did not decrease (Fig. 2).

Although his renal function transiently recovered, the patient began receiving renal replacement therapy in the form of hemodialysis about 2 years after starting everolimus therapy. Because of his TANDs, we considered that he would not effectively adapt to the new treatment environment and that it may cause panic. Therefore, before starting the hemodialysis therapy, we repeatedly simulated the therapy and allowed the patient to see the dialysis doctor and tour the dialysis room so that he could become acclimated to the dialysis environment. Additionally, the patient repeatedly visited with the staff members in the dialysis room so that he could recognize the dialysis room as a nonthreatening environment. With respect to controlling the patient's dry weight, we continued to provide nutritional guidance to his mother, who was his main caretaker.

\section{Mini-review of everolimus treatment for angiomyolipoma in patients with TSC \\ TSC and mTOR pathway}

TSC is an autosomal dominant genetic disorder with a birth incidence of 1 in 6000 to 10,000 people [5]. All patients with TSC carry loss-of-function germline mutations of the tumor suppressor gene TSC1 or TSC2 [6]. Hamartin and tuberin, which are encoded by $T S C 1$ and $T S C 2$, respectively, are components of the TSC protein complex. The TSC protein complex acts as an inhibitor of the mechanistic target of mTOR complex 1 (mTORC1), which plays an important role in regulating cell growth, proliferation, autophagy, and protein and lipid synthesis. Therefore, loss of TSC1/TSC2 function results in dysregulation of cell growth, metabolism, and the cell cycle with constitutive activation of mTORC1.

\section{Mutations in TSC1 and TSC2 and disease severity of TSC} Mutations in TSC1 and TSC 2 have been identified in about 70 and $20 \%$ of patients clinically diagnosed with TSC, respectively. The many TSC-causing mutations are distributed throughout the coding regions of both genes. All TSC clinical symptoms tend to be less severe overall in TSC1- than TSC2-associated disease [6]. Although there is great variability in disease expression, even among different patients and family members carrying the same mutations [6], several studies have demonstrated correlation between genotype and phenotype, including the nature and/or location of TSC1 and TSC2 mutations and a reduction of the intelligence quotient (IQ) or seizure severity [7-9]. With respect to the correlation between genotype and cognitive phenotype, $T S C 2$ is reportedly associated with a significantly lower IQ/developmental quotient (DQ) than TSC1 [7]. One study showed that in patients with TSC2 mutations, TSC2 protein-truncating and hamartin interaction domain mutations were significantly associated with lower intellectual outcomes, and TSC2 missense mutations and small in-frame deletions were significantly associated with a higher IQ/DQ [8]. With respect to correlations between genotype and the phenotype of infantile spasms, TSC2 mutations are significantly associated with a higher risk of infantile spasm compared with TSC1 mutations and the lack of mutations [9]. Although gene mutation analysis was not performed in the present case, our patient might have had mutations in TSC2 gene based on his clinical symptoms, including infantile spasms at 5 months of age, refractory epilepsy associated with delays in psychomotor development, severe intellectual disability, and a large renal angiomyolipoma.

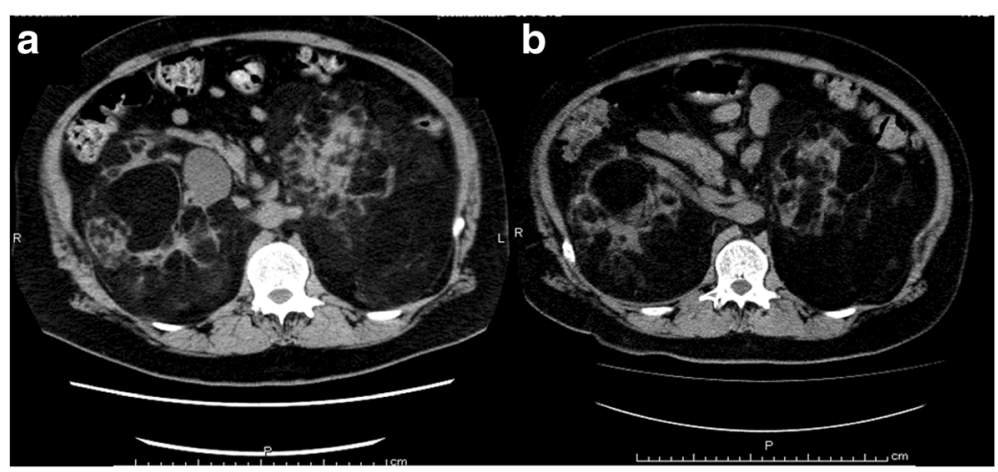

Fig. 2 Time course of abdominal CT images. Abdominal CT images a at initiation of everolimus treatment at 39 years old and $\mathbf{b} 5$ months after initiation of everolimus treatment. The right and left kidney sizes, measured as the longitudinal length of each kidney and calculated from slice counts of horizontal CT images, were 245 and 295 mm, respectively, at initiation of everolimus treatment and 250 and 300 mm, 5 months after initiation of everolimus treatment. CT, computed tomography 


\section{Effect of mTOR inhibitor treatment on renal angiomyolipoma and renal function}

Based on the hypothesis that cell metabolism can be altered by controlling hyperactivation of mTORC1, the oral mTORC1 inhibitor everolimus was evaluated as a treatment for renal angiomyolipoma in a phase 3, double-blind, placebo-controlled study called EXamining everolimus In a Study of Tuberous sclerosis complex (EXIST-2) [10]. This study showed that within a median time to response of 2.9 months, $42 \%$ of everolimus-treated patients and $0 \%$ of placebo-treated patients $(p<0.0001)$ had a confirmed angiomyolipoma response determined as a $>50 \%$ reduction in the total volume of the targeted angiomyolipoma relative to baseline. Long-term follow-up (median, 28.9 and 46.9 months in the everolimus- and placebo-treated patients, respectively) showed a 54 and $58 \%$ increase in the response rate, respectively, with an angiomyolipoma volume reduction in $97 \%$ of patients [11, 12].

With respect to renal function, adult patients with TSC have a high prevalence of prematurely diminished GFR [1]. This deterioration of kidney function may be due to surgery or embolization to treat acute bleeding from the angiomyolipoma, but it is also observed in patients who do not develop bleeding. In a study from the Netherlands, the TSC cohort showed an aging-related decline in GFR of $-1.53 \mathrm{~mL} / \mathrm{min} / 1.73 \mathrm{~m}^{2}$ per year, and $16 \%$ of patients had stage $>3$ chronic kidney disease (CKD) at some point during follow-up $[1,2]$. In the long-term follow-up of the EXIST-2 trials of everolimus, the GFR was maintained in patients with a normal GFR and 8 of 23 patients with a GFR of $<60 \mathrm{~mL} / \mathrm{min} / 1.73 \mathrm{~m}^{2}$ at baseline (including 3 patients with a GFR $<30 \mathrm{~mL} /$ $\min / 1.73 \mathrm{~m}^{2}$ at baseline) attained a GFR of $<30 \mathrm{~mL} /$ $\mathrm{min} / 1.73 \mathrm{~m}^{2}$ while on everolimus [12].

Our literature review revealed no reports describing the association between renal function and the size of the angiomyolipoma in patients with TSC who received everolimus treatment, although many reports have described reductions in the angiomyolipoma size or renal function during everolimus therapy.

\section{Discussion and conclusion}

Renal manifestations of TSC, including renal angiomyolipoma, renal cysts, and more rarely carcinomas, were found in $71 \%$ of a Japanese cohort [13]. Renal involvement is the most common cause of death in adult patients with TSC [1]. Adverse outcomes associated with renal angiomyolipoma can be acute, resulting from hemorrhage of a lesion, or can manifest as long-term renal failure because of a decrease in kidney function with progressive loss of normal renal parenchyma. In a study of a population in the Netherlands $[1,2], 16 \%$ of patients had stage $>3 \mathrm{CKD}$ at some point during the follow-up. The estimated overall risk of ESRD in patients with TSC ranges from about 1 to 7\% [1-4]. However, $20 \%$ of patients with TSC who develop ESRD die without renal replacement therapy, because dialysis is not considered feasible due to the patients' very low cognitive function [1]. Therefore, preservation of renal function is important for patients with severe TANDs.

Everolimus showed good efficacy in the abovementioned large, multicenter, prospective randomized trial (EXIST-2) [10, 11]. Analysis of the continuing EXIST-2 study has demonstrated increased efficacy and dramatically diminished adverse events [3]. The 2012 International Tuberous Sclerosis Complex Consensus Conference suggested that treatment with an mTOR inhibitor, including everolimus, is recommended as the most effective first-line therapy for asymptomatic growing angiomyolipoma [14]. Although some patients show deterioration in renal function, the long-term data in EXIST-2 suggest that the mean GFR remains stable, and a progressive decline was seen in patients who developed a GFR of $<30 \mathrm{~mL} / \mathrm{min} / 1.73 \mathrm{~m}^{2}$ during the studies [3]. In the current case, the patient had a Cr-eGFR of $13.7 \mathrm{~mL} /$ $\mathrm{min} / 1.73 \mathrm{~m}^{2}$ at the initiation of everolimus therapy and eventually showed a progressive decline. However, his Cr-eGFR recovered to $20.1 \mathrm{~mL} / \mathrm{min} / 1.73 \mathrm{~m}^{2}$ and was preserved at around $15 \mathrm{~mL} / \mathrm{min} / 1.73 \mathrm{~m}^{2}$ for close to 1 year after starting everolimus therapy. As a result, we could delay the initiation of renal replacement therapy for more than 1 year. This finding suggests that everolimus therapy may be a valuable treatment for patients with TSC even if they have an eGFR of $<30 \mathrm{~mL} / \mathrm{min} /$ $1.73 \mathrm{~m}^{2}$.

Deterioration of renal function may not be entirely attributable to hemorrhage of angiomyolipoma and subsequent treatment including surgery and embolization. Deterioration of renal function, including ESRD, in patients with TSC is thought to be mainly due to renal parenchymal loss secondary to angiomyolipoma and cyst growth [15]. In the current case, we treated the patient with the expectation that his renal function would be preserved with a decrease in the mass of the angiomyolipoma to that comparable with the normal renal parenchyma. However, although his renal function improved, CT showed neither morphological changes nor a reduction in the size of his bilateral kidney angiomyolipoma. Thus, it is difficult to explain these findings as caused by only renal parenchymal loss secondary to angiomyolipoma growth.

Kingswood et al. [16] proposed an additional hypothesis for the development of CKD: that TSC1 and TSC2 haploinsufficiency may lead to modest mTORC1 overactivity and therefore glomerular hypertrophy and hyperfiltration. Other authors have suggested that mTORC1 overactivity is a mechanism of CKD progression, especially in diabetic nephropathy [4]. Although 
the current patient did not have diabetes, he had developed severe obesity and his weight had been maintained at around $140 \mathrm{~kg}$ (body mass index $44.7 \mathrm{~kg} / \mathrm{m}^{2}$ ) since 28 years of age. He lost approximately $20 \mathrm{~kg}$ with a strict nutritional support service and had started to receive everolimus therapy. The finding that the patient's renal function was preserved following a reduction in weight and everolimus treatment supports the hypothesis of the development of CKD proposed by Kingswood et al. [16].

In conclusion, everolimus treatment successfully delayed the initiation of renal replacement therapy in a patient with ESRD due to a large angiomyolipoma in the bilateral kidneys, although only temporarily. Everolimus therapy may be a valuable treatment for patients with TSC with severe TANDs even if they have compromised renal function. However, because the patient's eGFR eventually deteriorated after temporary preservation of renal function, everolimus therapy should be started in the early stage of TSC. The observation that everolimus therapy and weight loss appeared to effectively preserve renal function suggests that a mechanism for the development of CKD might be mTORC1 overactivity by TSC1 or TSC2 haploinsufficiency with resultant, glomerular hypertrophy and hyperfiltration.

\section{Abbreviations}

CKD: Chronic kidney disease; CT: Computed tomography; eGFR: Estimated glomerular filtration rate; ESRD: End-stage renal disease; EXIST-2: EXamining everolimus In a Study of Tuberous sclerosis complex; GFR: Glomerular filtration rate; $\mathrm{mTORC1:} \mathrm{mTOR} \mathrm{complex} \mathrm{1;} \mathrm{TANDs:} \mathrm{Tuberous} \mathrm{sclerosis}$ complex-associated neuropsychiatric disorders; TSC: Tuberous sclerosis complex

\section{Acknowledgements}

We thank Alexander Pishief, LLB, BBmedSc, and Angela Morben, DVM, ELS, from Edanz Group (http://www.edanzediting.com/ac) for editing a draft of this manuscript.

\section{Availability of data and materials}

The data sets used and analyzed during the current study are available from the corresponding author on reasonable request.

\section{Authors' contributions}

$A A, H M, Y F, H N, A S$, and $H T$ discussed the therapy and treated the patient. $\mathrm{AA}, \mathrm{HM}$, and $\mathrm{YF}$ collected the patient data and contributed to the radiologic estimation and interpretation of the size of the bilateral kidneys. AA wrote the manuscript and is responsible for its contents. HN, AS, and HT reviewed and critically revised the manuscript. All authors read and approved the final version of the manuscript.

\section{Ethics approval and consent to participate}

The manuscript and informed consent form were approved by the ethics committee of Osaka Medical College (approval number: 2017-OMC-2).

\section{Consent for publication}

Because the patient had severe intellectual disability due to TANDs, we gave the patient's mother an opportunity to read the manuscript and obtained her written consent for publication.

\section{Competing interests}

Hiroshi Tamai received a lecture fee from Novartis Pharma. The other authors declare that they have no competing interests.

\section{Publisher's Note}

Springer Nature remains neutral with regard to jurisdictional claims in published maps and institutional affiliations.

\section{Author details}

'Department of Pediatrics, Osaka Medical College, 2-7 Daigaku-machi, Takatsuki City, Osaka 569-8686, Japan. ${ }^{2}$ Blood Purification Center, Arisawa General Hospital, 12-14 Higashinomachi, Nakamiya, Hirakata City, Osaka 573-1195, Japan. ${ }^{3}$ Department of Pediatrics, Hirakata City Hospital, 2-14-1 Kinyahonmachi, Hirakata City, Osaka 573-1013, Japan.

Received: 16 March 2018 Accepted: 20 May 2018

Published online: 20 June 2018

\section{References}

1. Ejikemans MJC, van der War W, Rejinders LJ, Roes KCB, van Waalwijk van Doom-Khosrovani SB, Pelletier C, Magestro M, Zonnenberg B. Long-term follow-up assessing renal angiomyolipoma treatment patterns, morbidity, and mortality: an observational study in tuberous sclerosis complex patients in the Netherlands. Am J Kidney Dis. 2015;66:638-45.

2. Vekeman F, Magestro M, Karner P, Duh MS, Nichols T, van Waalwijk van Doorn-Khosrovani SB, Zonnenberg BA. Kidney involvement in tuberous sclerosis complex: the impact on healthcare resource use and costs. J Med Economics. 2015;18:1060-70

3. Bissler JJ, Kingswood JC. Optimal treatment of tuberous sclerosis complex associated renal angiomyolipoma: a systematic review. Ther Adv Urol. 2016;8:279-90.

4. Declèves $A E$, Sharma K. Novel targets of antifibrotic and anti-inflammatory treatment in CKD. Nat Rev Nephrol. 2014;10:257-67.

5. Martin KR, Zhou W, Bowman MJ, Shih J, Au KS, Dittenhafer-Reed KE, Sisson KA, Koeman J, Weisenberger DJ, Cottingham SL, DeRoos ST, Devinski O, Winn ME, Cherniak AD, Shen H, Northrup H, Krueger DA, Mackeigan JP. The genomic landscape of tuberous sclerosis complex. Nat Commun. 2017; https://doi.org/10.1038/ncomms15816.

6. Henske EP, Jóźwiak S, Kingswood JC, Sampson JR, Thiele EA. Tuberous sclerosis complex. Nat Rev Disease Primers. 2016; https://doi.org/10.1038/ nrdp.2016.35.

7. Wong HT, McCartney DL, Lewis JC, Sampson JR, Howe CJ, de Vries PJ. Intellectual ability in tuberous sclerosis complex correlates with predicted effects of mutations on TSC1 and TSC2 proteins. J Med Genet. 2015;52:815-22.

8. van Eeghen AM, Black ME, Pulsifer MB, Kwiatkowski DJ, Thiele EA. Genotype and cognitive phenotype of patients with tuberous sclerosis complex. Eur J Hum Genet. 2012;20:510-5.

9. van Eeghen AM, Nellist A, van Eeghen EE, Thiele EA. Central TSC2 missense mutations are associated with a reduced risk of infantile spasms. Epilepsy Res. 2013;103:83-7.

10. Bissler JJ, Kingswood JC, Radzikowska E, Zonnenberg BA, Frost M, Belousova E, Sauter M, Nonomura N, Brakemeier S, de Vries PJ, Whittemore VH, Chen D, Sahmoud T, Shah G, Lincy J, Lebwohl D, Budde K. Everolimus for angiomyolipoma associated with tuberous sclerosis complex or sporadic lymphangioleiomyomatosis (EXIST-2): a multicenter, randomized, doubleblind, placebo-controlled trial. Lancet. 2013;381:817-24.

11. Bissler JJ, Kingswood JC, Radzikowska E, Zonnenberg BA, Frost M, Belousova E, Sauter M, Nonomura N, Brakemeier S, de Vries PJ, Berkowitz N, Miao S, Segal S, Peyrard S, Budde K. Everolimus for renal angiomyolipomas in patients with tuberous sclerosis complex or sporadic lymphangioleiomyomatosis: extension of a randomized controlled trial. Nephrol Dial Transplant. 2016:31:111-9.

12. Bissler JJ, Kingswood JC, Radzikowska E, Zonnenberg BA, Belousova E, Frost MD, Sauter M, Brakemeier S, de Vries PJ, Berkowitz N, Voi M, Peynard S, Budde K. Everolimus long-term use in patients with tuberous sclerosis complex: four-year update of the EXIST-2 study. PRoS ONE. 2017;12(8):e0180939.

13. Wataya-Kaneda M, Tanaka M, Hamasaki T, Katayama I. Trends in the prevalence of tuberous sclerosis complex manifestations: an epidemiological study of 166 Japanese patients. PLoS One. 2013;8:e63910.

14. Krueger DA, Northrup H, for the International Tuberous Sclerosis Complex Consensus Group. Tuberous sclerosis complex surveillance and management: recommendation of the 2012 International Tuberous Sclerosis Complex Consensus Conference. Pediatr Nerurol. 2013;49:255-65. 
15. Waele LD, Lagae L, Mekahli D. Tuberous sclerosis complex: the past and the future. Pediatr Nephrol. 2015;30:1771-80.

16. Kingswood JC, Bissler JJ, Budde K, Hulbert J, Guay-Woodford L, Sampson JR, Sauter M, Cox J, Patel U, Elmslie F, Anderson C,

Zonnenberg BA. Review of the tuberous sclerosis renal guidelines from the 2012 consensus conference: current data and future study.

Nephron. 2016;134:51-8.

Ready to submit your research? Choose BMC and benefit from:

- fast, convenient online submission

- thorough peer review by experienced researchers in your field

- rapid publication on acceptance

- support for research data, including large and complex data types

- gold Open Access which fosters wider collaboration and increased citations

- maximum visibility for your research: over $100 \mathrm{M}$ website views per year 